\title{
MOTIVATION AND CONFIDENCE OF INDONESIAN TEACHERS TO USE ENGLISH AS A MEDIUM OF INSTRUCTION
}

\author{
Mangasa Aritonang \\ (ma22@students.waikato.ac.nz) \\ The University of Waikato \\ Private Bag 3105, Hamilton 3240, New Zealand
}

\begin{abstract}
This research paper investigates the motivation and confidence of Indonesian teachers of non-English to learn English and to use it as a medium of instruction resulting from their participation in a blended learning course. The purpose of the English learning for this particular group of teachers was to enable them to create English-speaking teaching and learning environment. Such environment is perceived as necessary to enhance English language learning and acquisition in some Indonesian vocational schools. The levels of motivation and confidence have been an issue because they potentially either contribute to or hinder English language learners to learn and use English for interactions. This qualitative research was undertaken using an interpretive research paradigm and a case study approach. Qualitative research data were collected from multiple sources such as indepth interviews, observation notes, online interaction script, and reflective journals of the participants. Quantitative data were collected through surveys to add meaning to the qualitative data. The research revealed varying increase in the levels of motivation and confidence of the participants. Transformation of extrinsic to intrinsic motivations appeared to occur. Contributing factors to the increase of the motivation and confidence are discussed in this paper.
\end{abstract}

Keywords: motivation, confidence, blended-learning, transformation

Motivation has been acknowledged as an important element for success in the second or foreign language learning by researchers (Dörnyei, 2003; Gardner \& MacIntyre, 1991; Lucas et al., 2010; Ushioda, 2001, 2011). Motivation is defined as "a theoretical construct used to explain the initiation, direction, intensi- 
ty, persistence, and quality of behaviour, especially goal-directed behaviour" (Brophy, 2010). Researchers stated that motivation is a critical issue in both blended learning course (Dzakiria, Mustafa, \& Bakar, 2006) and full e-learning course (Craig \& Perraton, 2003). Previous research (Woltering, Herrler, Spitzer, \& Spreckelsen, 2009) showed that learners' motivation to solve case in blended learning mode increased because learners found blended learning mode realistic, descriptive, and very practical. Learners also appreciated the flexibility offered in blended learning course. However, the research undertaken by Woltering et al. (2009) also showed that few learners were not satisfied with the blended learning approach and caused low motivation. Unfortunately, there was no further study to investigate what caused the dissatisfaction of the learners and decreased the motivation. Brock (2003) suggests motivation to learning as one of three competence dimensions to consider in designing online learning. The other two competence dimensions were basic literacy and computer literacy (Brock, 2003). Similarly, Craig \& Perraton (2003) mentioned that "motivation is a critical factor in ensuring that opportunities for continuing professional development are in fact used" (p.108). This statement was relevant to the situation of this research context. I perceived that motivation played an important role for teacher participants to decide their participation in the blended learning course.

In their research, Craig and Perraton (2003) discussed several ideas related to teachers' motivation to participate in online learning for professional development. One of the ideas they discussed was about the relevance of the learning material, especially in the context of teacher professional development (Craig \& Perraton, 2003). Teachers need to understand what they are going to learn in the blended learning course, and that it has to be relevant to their teaching job as emphasized in the principles of adult learning. This idea was one of the important things to consider in the design of the present research. The need of the Indonesian teachers was English language communication skills to use for classroom instruction, and therefore, classroom expressions in English language were the main content of the blended learning course.

Another idea discussed in previous research to increase teachers' motivation to participate in online learning was to provide incentives or rewards to teachers participating in the online learning (Craig \& Perraton, 2003). To some 
extent, I perceived that this idea was good and potential to increase teachers' motivation. The secure, permanent status of teachers was another factor discussed in relation to teachers' motivation to participate in a professional development course. In China, this permanent status of teachers known as "iron rice bowl" (Craig \& Perraton, 2003; Paine \& Fang, 2006) made teachers reluctant to participate in professional development. Therefore, China has challenged that status by introducing teacher contracts. This means that teachers are regularly inspected and evaluated, and possible to be fired if not satisfactorily meet the requirement. With the status of teachers as secure government employees, teachers are safely staying in a comfort zone simply by doing their regular teaching jobs. The state of teachers' permanent employment also exists in Indonesian context, especially in public schools. Slightly different from China that adopted teacher contracts for reward and punishment policy, the government of Indonesia applied certification program to encourage teachers to participate in professional development courses. According to the law number $14 / 2005$ about teachers and lecturers, certification is a formal recognition to teachers as professional teachers and thus receive additional financial income (President of Republic of Indonesia, 2005).

In addition to the job security and reward and punishment reasons, Brock (2003) added some other reasons that motivated participation in online learning, such as eagerness to develop new skill, striving for a personal learning goal, and joining friends in a common event. I noticed that most of the motivations discussed are more extrinsic rather than intrinsic motivation. This seems to commonly happen to adult learners because of their working circumstances.

Confidence in using the target language for communication is also seen as an important role in the success of second or foreign language learning. Confidence is seen as an element of emotion (Barbalet, 1998), emotional reaction to prior experience (MacIntyre, Dörnyei, Clément, \& Noels, 1998), an element of affective factors (Mahn \& John-Steiner, 2002), and an integral part of practical actions (Roth, 2007). It is confidence that influence individuals to behave the way they do. Considerable researches (Clement, Dornyei, \& Noels, 1994; MacIntyre et al., 1998; MacIntyre \& Gardner, 1991; Mahn \& John-Steiner, 2002; Ware, 2004; Wu, Yen, \& Marek, 2011) investigated confidence in the second language area. Research suggests that confidence is closely related to the willingness to communicate (WTC) in second language. In a study about 
heuristic model of variables influencing willingness to communicate, confidence is categorized as state communicative self-confidence and second language (L2) self-confidence. These two categories are positioned in two layers: situated antecedents and motivational propensities respectively (MacIntyre et al., 1998). Within the layer of situated antecedents, state communicative selfconfidence together with the desire to communicate with a specific person is positioned as immediate precursors of WTC at a given moment in time. On the other hand, within the motivational propensities, L2 self-confidence, together with interpersonal motivation and intergroup motivation, is positioned as stable, enduring influences to WTC. However, the two categories of confidence have underlying commonalities as confidence constructs: language anxiety and self-evaluation. Language anxiety refers to emotional reaction to prior experiences whereas self-evaluation refers to self-perceived competence to effectively use the second language.

To increase the self-confidence of the learners, researchers suggest that several conditions need to be created in a blended learning environment. A blended learning approach to prepare postgraduate students as graduate teaching assistants in Singapore (McClure, 2007) was reported as having been effective to increase self-confidence because it "encouraged self-reflection and selfevaluation, supported collaborative learning and problem solving skills, and facilitated tasks requiring analysis and evaluation of real life teaching situations" (p. 660). It was argued that supportive relationship between the international students and course coordinator increased the self-confidence of international students to teach in English. Similarly, Collis \& Jung (2003) stated that in order to increase the confidence, teachers participating in professional activities and learning through ICT need to feel that they are supported (Collis \& Jung, 2003). One way to obtain that support is through the learning community created in the blended learning approach. From building a sense of professional community in the blended learning approach, teachers as learners in the blended learning course learn from their peers and obtain supports. Another condition was also suggested that person-centred in blended learning paradigm increased self-confidence of the learners (Motschnig-Pitrik \& Mallich, 2004). Reflecting from the previous research related to increasing confidence in a blended learning approach, I perceived that a carefully-designed blended learning course helps to increase the confidence of the learners. 
This research examines if learning English using a blended learning approach had impacts on the change of motivation and confidence of Indonesian teachers of non-English in learning English and using it as a medium of instruction. Even though rewards and punishment, that were claimed as crucial factors to trigger motivation (Craig \& Perraton, 2003; Paine \& Fang, 2006), were absent in the blended learning course, the teacher participants reported that their motivation and confidence had increased. Transformation of extrinsic to intrinsic motivation appeared to occur. All participants reported that their integrative or intrinsic motivation had become strong and very strong after the blended learning course. For some participants, the level of instrumental orientation or extrinsic motivation was simultaneously lowered and weakened.

I perceive that using English as a medium of instruction by teachers of non-English is an effort to create an English-speaking environment at school. An English speaking environment was considered necessary to enhance the English language communication skills of students because students had very limited contact hours for English. To create the English-speaking environment, the Indonesian government once made a policy for selected schools to use English as a medium of instruction in mathematics, science, and vocational training courses. To enable the teachers of these subjects to use English language in the classroom, an English language training course using a blended learning approach was offered.

\section{METHOD}

This interpretive qualitative research used a case study method. Sixteen teachers of mathematics, science, and vocational training courses from three different schools participated in the research. A four-month English language learning course was offered to the participants using a blended learning approach: a combination of face-to-face tutorials and online learning interactions. Facebook and Edmodo were used as the platform for the online learning interaction. In addition to my role as a researcher, I also served as the learning facilitator in the blended learning course.

In the face-to-face tutorials, participants discussed and practised English expressions commonly used in the classroom within their own school environment. Relevant reading and grammatical knowledge was also discussed when 
necessary. The participants also undertook microteaching sessions through which they practised to use English as a medium of instruction and received constructive feedback from peers as well as from me as the learning facilitator. In the online interactions, all participants from three different schools socially interacted and discussed content-related issues. To enhance the English learning and acquisition, teacher participants were encouraged to use English in the online interaction.

After the four-month learning, I observed individual participants in their classroom while using English as a medium of instruction. The forty-five minute class observation was undertaken twice over two months. However, three out of the sixteen participants were also observed in their classroom during the first week of the blended learning course. This observation was the initiative of the three participants because they needed feedback on their English.

The data were obtained through observation notes, recorded interviews, participants' reflective journals, and the online interaction scripts. The qualitative data were analysed by using Braun and Clarke's (2006) thematic analysis and content analysis (Braun \& Clarke, 2006). Nvivo 10 was used to categorize the data during the data analysis process. To complement the data, pre-and post-surveys were also undertaken and analysed descriptively. Fifteen statements in the survey (Appendix 1) were given to participants as a pre-and postsurvey. The survey included statements about confidence (1-4), motivation (512), and the amount of English used by the participants in their teaching (1315). Within the statements regarding motivation, two statements (statements 5 and 9) were categorized into intrinsic motivation and five statements (statements $6,7,8,10$, and 11) were categorized into extrinsic motivation. One statement (statement 12) was categorized as neutral (amotivation) which indicated no or lack of interest in learning English (Deci \& Ryan, 1985; Vallerand, 1997).

\section{FINDINGS AND DISCUSSION}

\section{Findings}

The research indicated that participation in the blended learning course increased the level of motivation and confidence of teacher participants to learn 
and use English as a medium of instruction. The following section describes the changes in motivation as well as in confidence that were experienced by the teacher participants and discusses some factors that contributed to these changes.

\section{Changes in Motivation}

During the interview sessions, the motivation of participants was categorized into four levels: (1) very unmotivated, (2) unmotivated, (3) motivated, and 4 very motivated. The interview data indicated that the level of motivation of all participants changed in different ranges. Six out of the sixteen participants mentioned that their level of motivation had changed from (2) unmotivated to (4) very motivated; five participants from (2) unmotivated to (3) motivated; four participants from (3) motivated to (4) very motivated; and one participant from (1) very unmotivated to (3) motivated. No participant exhibited a large movement from (1) very unmotivated to (4) very motivated. However, there was an indication of fluctuating levels of motivation during their participation in the blended learning. The absence or lack of support from the school management and the positive response from students were reported as having contributed to the fluctuating motivation.

Using English in a class is a part of school program but there is no feedback from the school management. For me sometimes I am motivated because the students give me good responses. (Interview: P1)

Data from surveys, though slightly different, confirmed the positive changes in the participants' motivation: a change from negative to positive domain. This implies that these participants were initially less motivated but became more motivated after their participation in the blended learning course. Some other participants remained in the positive domain: "agreeing" and "strongly agreeing" in their responses to some statements.

As the surveys asked participants to respond by agreeing or disagreeing to statements about different motivations in the survey, I converted the options 1 (strongly disagree) to 4 (strongly agree) into qualitative descriptions to describe the levels and meaning of the integrative motivation as indicated in Table 1. 
Table 1. Conversion Table to Describe the Levels of Integrative Motivation

\begin{tabular}{llll}
\hline No. & Options & Levels of motivation & Meaning \\
\hline 1 & Strongly disagree & Very weak & Very unmotivated \\
2 & Disagree & Weak & Unmotivated \\
3 & Agree & Strong & Motivated \\
4 & Strongly disagree & Very strong & Very motivated \\
\hline
\end{tabular}

To better understand the finding, it is necessary to look at the changes in the intrinsic (integrative) and extrinsic (instrumental) motivations of the teachers. The two integrative-motivation statements indicated that all participants were positioned in the positive domain $(4=$ very strong and $3=$ strong) of the intrinsic motivation at the end of the blended learning course as shown in Table 2 .

Table 2. Number of Responses to Integrative Motivation

\begin{tabular}{lll}
\hline Motivation changes & S5 & S9 \\
\hline Remain very strong (4) & 7 & 6 \\
Remain strong (3) & 2 & 5 \\
From strong (3) to very strong (4) & 5 & 4 \\
From very weak (1) to strong (3) & 2 & 1 \\
Total & 16 & 16 \\
\hline
\end{tabular}

For statement 5, seven participants remained very strong (4), and two participants remained strong (3). Five participants reported the change from 3 (strong) to 4 (very strong), and two participants from 1 (very weak) to 3 (strong). For statement 9, six participants remained very strong (4), five participants remained strong (3), four participants changed from strong (3) to very strong (4), and one participant from very weak (1) to strong (3). Thus, after the blended learning course, all participants perceived that they had strong and very strong integrative motivation even though some of them started with selfreported weak and very weak motivation. Figure 1 shows the aggregated data on the participants' perceived change in integrative motivation. 
Participants' Mean Self-Reported Change in Integrative Motivation

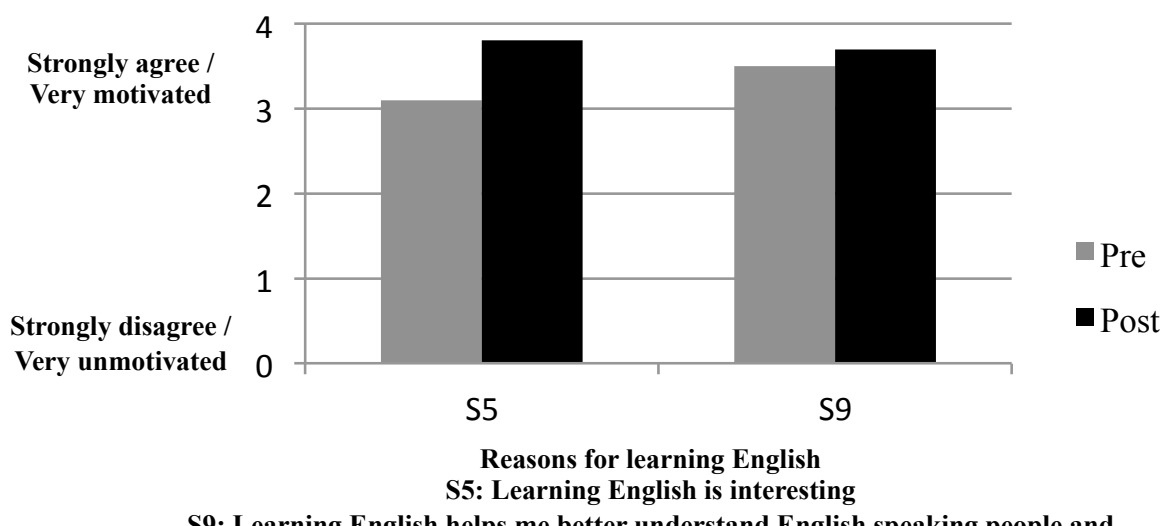

S9: Learning English helps me better understand English speaking people and

Figure 1. The Mean Self-Reported Change in Integrative Motivation 2.

Changes also occurred in the instrumental motivation as shown in Figure

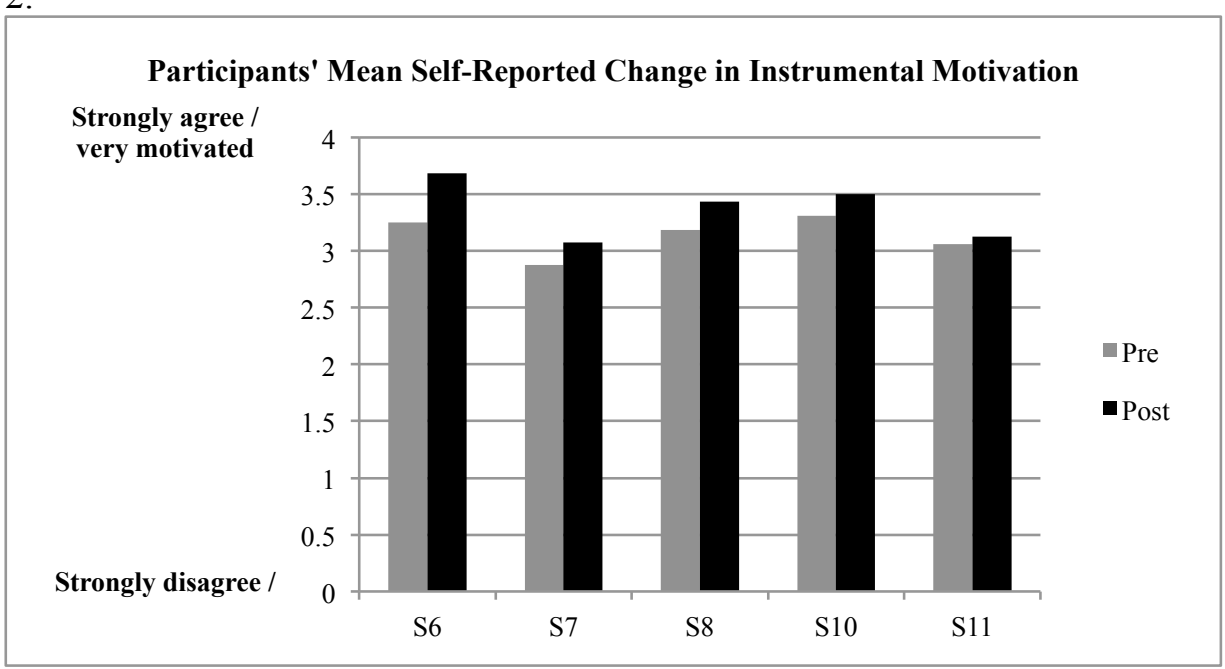

Figure 2. The Mean Self-Reported Change in Instrumental Motivation 
The aggregated data as in Figure 2 shows very little change in the instrumental motivation because the sixteen participants reported different categories of responses: some participants remained very strong (4) and strong (3) some remained weak, some changed to stronger levels of motivation, and some others changed toward lower levels of motivation such as from very strong (4) to strong (3) and from strong (3) to weak (2). The change of instrumental motivation to weaker levels of motivation signalled the significance of the participation in the blended learning course. This implies that the level of instrumental orientation was lowered and weakened whereas, at the same time, the level of integrative or intrinsic motivation is higher and strengthened. I perceived the self-reported changes in integrative and instrumental motivation as noticeable.

Concerning the response to the amotivation to learn English (statement 12), five participants reported that they initially had no or little interest in learning English but gradually became interested. This means that there was a change from amotivated to motivated as highlighted in Table 3 . The other eleven participants who remained in 1 (very weak) and 2 (weak) indicated that they did not agree with statement number 12, instead, they remained to have interest to learn English.

Table 3. Number of Responses to Amotivation Statement

\begin{tabular}{ll}
\hline Motivation changes & No of participants \\
\hline Remain very weak (1) & 9 \\
Remain weak (2) & 2 \\
*From strong (3) to very weak (1) & 3 \\
*From weak (2) to very weak (1) & 2 \\
Total & 16 \\
\hline
\end{tabular}

* Changes to opposite (weaker) motivation

\section{Changes in Confidence}

Information from across the dataset confirmed that participation in the blended learning course was associated with the change of teacher participants' confidence in using English as a medium of instruction. The confidence of all participants increased in different ranges. For example, interview data indicated that eight out of sixteen participants had changed from (2) unconfident to (3) confident; three participants from (1) very unconfident to (3) confident; three 
participants from (2) unconfident to (4) very confident, and two participants from (3) confident to (4) very confident.

Data from surveys also confirmed that changes in the level of confidence had occurred. The four confidence-related statements included confidence using English in different contexts: in daily conversation with friends (S1), in daily informal conversation with students (S2), for classroom managment only (such as greetings, managing question and answer, providing feedback, and closing) (S3), and for content delivery (S4). Each statement included six options that ranged from 1 to 6 with 1 being highly unsure and 6 highly confident. The aggregated self-report data for statements 1 to 4 are shown in Figure 3.

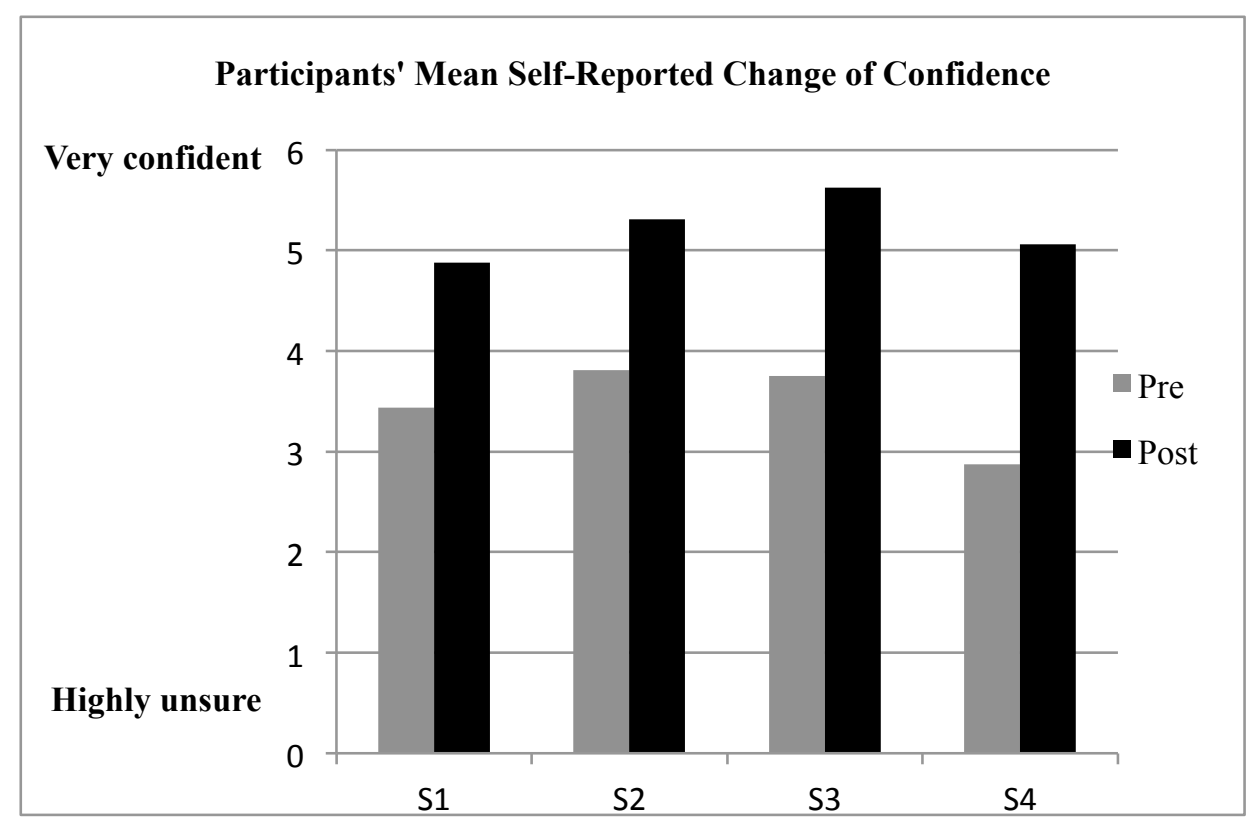

Figure 3. Participants' Mean of Self-Reported Change in Confidence

\section{Factors Impacting on Changes in Motivation and Confidence}

Participants reported some internal and external factors that had impacts to the change of their motivation and confidence. External factors included positive response from students, feedback from peers, the environment in the 
blended learning course, and the school's policy. Internal factors included the awareness of participants on the significance of having good English proficiency and on the responsibility to help students.

Positive response from students was reported as having affected the change on the level of motivation and confidence. Four participants reported that positive responses from students contributed to the increase of their confidence. The online interaction script as well as my observation notes confirmed this report. When teachers used English instead of Indonesian for classroom instruction, they reported that students were more focused to listen and tried to understand.

I feel very motivated to use English in the classroom because my students become more active to use English, too. They are also trying to give greeting and answer my classroom by using English. ... It made me very confident to use English in the classroom. (Interview: P4)

I tried to teach by using more English today at $\mathrm{X}$ grade, and they gave me very good responses. Surprisingly, they can understand all of my instructions and they tried to answer me in English too. I gave them one exercise in English, and they could understand it with no translation. How happy I am. (Online interaction)

Another teacher was of the view that using English in the classroom was a way to motivate students to improve their English.

After the program, I think, I can rate it three, motivated, because if we speak English frequently, and we want to motivate the students, we must be highly motivated to speak English. If I learn English, my students will be motivated too. (Interview: P3)

Motivation also came from peers. For example, one participant reported that he became motivated to learn when he observed other participants speaking in English.

I can see my friends using their good English, and I hope I can motivate myself. .. so I can learn from my friends and comment in the group Facebook. (Interview: P15) 
The opportunity to learn together with friends in the blended learning course was also seen as a supporting factor to increasing motivation. This is consistent with what Brophy (2010) said that sharing the same belief "we are all learning together" contributed to create a learning cohort (Brophy, 2010) and thus increased motivation.

Feedback from peers contributed to the increased confidence in using English in the classroom. The feedback was obtained from peers when the participants developed a lesson plan, when they undertook teaching practices in the micro teaching sessions, and when they posted problems in online interaction. For example, P1 reported that feedback from peers made her more confident. The data from online interaction also supported this report.

"Before this study, we had a program using English in the class. At that time I had good confidence. But after that, there was no feedback. I became unconfident again. And then, after following this study, I got lots of experiences, I got lots of interactions, discussions, a lot of feedback, and I see my students' response, now I am very confident". (Interview: P1)

"I presented my material about multimeter in micro teaching class today (it is a challenge for me), and I tried my best to make a good presentation, and thanks to all my friends who became my audience today. From now on I'm more confident to speak in English". (Online interactions).

All participants reported that their learning experiences in the blended learning course had provided them with more positive perspectives about using English as a medium of instruction, and thus made their confidence to use it in the classroom greater. The learning experience included the collaboration with peers and the teaching practices.

Joining this program made me practise using English in the classroom and I feel my motivation increased. (Interview: P6)

Ya, more motivation because of my first experience teaching in English in the classroom. I can give the students something in the classroom. (Interview: P16)

I think English is very important, not only for me but also for my students. I try using English step by step like eee... for greetings, give motivation for my 
students, and then I try using English for explaining my materials together with my students. I know that eerr..my students in the future need to using English for ee...for working in the office, and..for social life, so English in the classroom is important.(Interview: P4)

Related to this confidence, once when we had discussion online, there's a comment that it's OK if we make some mistakes in grammar because we are still learning English as a foreign language. So, it doesn't matter if we make some mistakes as long as we can understand each other. (Interview: P1)

I think because we join the program, so our vocabulary improved, our practice improved, our English improved, our experience improved, ... our knowledge of English improved, so our confidence is very high now. (Interview: P9)

Internal factors included the awareness of participants: being aware of the significance of having good English proficiency, and of the responsibility to help students in their English language learning.

But I keep making them feel that using English in the classroom is not just about the policy, it's more like how we practise our English. When we learn something, it is never useless. (Interview: P1)

...because I realize that English is very important for us. We can get more knowledge from English. (Interview: P6)

It is good to start using English in the classroom. It is the responsibility of all teachers to create English speaking environment in the classroom. (Online interaction)

I think it is not wrong if we speak English, even only me who is speaking English, only me and my students, I just try to speak English to improve my skill in speaking English. (Interview: P3)

\section{Discussion}

The two forms of awareness (the significance of having good English communication skills and the responsibility to help students in their English learning) were perceived as internal factors that contributed to the increased 
motivation of participants. These two forms of awareness are categorized as internal regulation or self-regulation (Wertsch, 2008), intrapsychological function (Vygotsky, 1978), intrinsic motivation (Deci \& Ryan, 1985), and integrative orientation (Gardner, 1985). It is then necessary to investigate what made the participants became aware of the two conditions.

The changes of extrinsic-motivation to weaker levels and the intrinsicmotivation to stronger levels signalled the significance of participation in the blended learning course. As mentioned earlier that positive feedback, communication, or rewards as social-contextual events promotes the feeling of being competent and enhance intrinsic motivation (Ryan \& Deci, 2000; Vallerand, 1997). The social-contextual events including the positive feedback that the participants received in the blended learning course was perceived as having been powerful to make the teachers feel more competent, and thus changed their perspectives and made them become intrinsically motivated. The participants' social interactions in the blended learning course appeared to be powerful to transform their other regulation (extrinsic motivation) into self-regulation (intrinsic motivation).

Previous researches suggest that extrinsic motivation that is also known as instrumental motivation is potentially transformed to intrinsic or integrative motivation through an intervention. For example, researchers (Deci \& Ryan, 1985; Dweck, 2008; Ryan \& Deci, 2000; Vallerand, 1997; Vygotsky, 1978; Wertsch, 2008; Yovetich \& Rusbult, 1994) signalled the possibility of transforming of extrinsic motivation into intrinsic motivation. The transformation process involves internalization and integration. Firstly, Wertcsh (2008), adopting Vygotsky's (1978) concept of egocentric speech, claimed that the external regulation or interpsychologial function is likely to be transformed into internal or self-regulation or intrapsychological function. Wertsch (2008) suggested that interactions at external level involve some degree of self-regulation. I presume that this self-regulation plays an important role to transform the extrinsic motivation into intrinsic motivation. Wertsch (2008) reported the analogy of such transformation following Vygotsky's (1978) perspective on egocentric speech that reflects a new functional capacity for speech - self-regulation - and that it gradually becomes internalized (goes underground) as inner speech. Secondly, Vallerand (1997) suggested that positive feedback has potential to make learners feel more competent, and in turn, the feeling of being competent is also po- 
tential to make the learner intrinsically motivated. Vallerand (1997) illustrated an example about this. When a learner receives positive feedback, he or she will feel more competent. When the learner feels more competent, the more likely he or she will be intrinsically motivated. Thirdly, in his study of personality, Dweck (2008) claimed that intervention brought about important changes to personality and adaptive functioning. It was argued that socialization process and experience in a small intervention was potentially shaping self-theories and mental representations (Dweck, 2008). Similarly, McGroarty (2001) also argued that the role of the social context of the learning activities contributed to the contextualization of language learning motivation (McGroarty, 2001). Fourthly, Deci and Ryan (1985) introduced internalization and integration of values and behavioural regulations in their self-determination theory (SDT). This concept of internalization and integration of values and behavioural regulations signalled the transformability of extrinsic motivation into intrinsic motivation. Lastly, another study was conducted by Yovetich and Rusbult (1994) about accommodative behaviour in close relationship. They reported that the motivation of students who participated in the study was transformable (Yovetich \& Rusbult, 1994). This study confirmed that instrumental or extrinsic motivation is transformable into intrinsic motivation.

The confidence of teacher participants to use English as a medium of instruction was reported to have increased after their participation in the blended learning course. Because confidence is subjective, it may be judged differently by different people (Bowman, 2014). It was the teacher participants who experienced the changes of confidence and therefore, the self-reported data were very important to my research. However, self-reported data alone were not sufficient. Data from other sources were required to validate the self-reported data. For this data triangulation, my research observation notes were notable and consistent with the teacher participants' own perceptions of their changed confidence. Even though confidence is intangible, the level of nervousness that was observable indicated the level of confidence. I assumed that the lower the level of nervousness, the higher the level of confidence was. My observation notes showed that teacher participants were less nervous in using English in the classroom during the second observation. Some examples of behaviours that indicated the nervousness were the shaking body, speech, and gestures. Thus, 
Aritonang, Motivation and Confidence of Indonesian Teachers 163

the self-reported data and my observation notes confirmed the increase of participants' confidence.

\section{CONCLUSIONS AND SUGGESTIONS}

One of the more significant findings to emerge from this research is that the participation in the blended learning course appeared to increase the level of motivation and confidence of teacher participants to learn and use English as a medium of instruction. External and internal factors contributed to the change in the levels of motivation and confidence. Participation in the blended learning course appeared to have been powerful to transform the extrinsic motivation to intrinsic motivations of the teacher participants. It was shown that the socialcontextual interactions in the blended learning course trigger the intrinsic motivation and confidence of the teachers. Thus, blended learning approach enabled Indonesian teachers of non-English to support an English-speaking atmosphere at school. The English-speaking environment enhanced the English learning and acquisition of students and teachers.

The findings of this study have a number of important implications for future practice, especially for language policy at schools. Teachers of nonEnglish are more likely to support English-speaking environment at school provided that they are given opportunities to sustain their English learning. The online-learning interaction offered in a blended learning approach supports the efforts to sustain the English learning. The blend of face-to-face and online learning appeared to be more effective for teacher development courses in Indonesia, especially because Indonesian teachers are distributed in different islands due to the geographical conditions.

\section{REFERENCES}

Barbalet, J. M. (1998). Emotion, social theory, and social structure: A macrososiolingual approach. Cambridge, NY: Cambridge University Press.

Bowman, K. (2014). More than words: Observing changes in confidence. Retrieved from http://policy-practice.oxfam.org.uk/blog/2014/02/morethan-words-observing-changes-in-womens-confidence 
Braun, V., \& Clarke, V. (2006). Using thematic analysis in psychology. Qualitative Research in Psychology, 3(2), 77-101. doi: 10.1191/ 1478088706qp063oa

Brock, R. (2003). Increasing learner involvement and participation. In G. M. Piskurich (Ed.), The AMA handbook of e-learning: Effective design, implementation, and technology solutions (pp. 99-115). New York, NY: AMACOM.

Brophy, J. (2010). Motivating students to learn (3rd ed.). New York, NY: Routledge

Clement, R., Dornyei, Z., \& Noels, K. A. (1994). Motivation, self-confidence, and group cohesion in the foreign language classroom. Language Learning, 44(3), 417-448.

Collis, B., \& Jung, I. (2003). Uses of information and communication technologies in teacher education. In B. Robinson \& C. Latchem (Eds.), Uses of information and communication technologies in teacher education: World review of distance education and open learning (Vol. 3, pp. 171-192). London, UK: Routledge/Falmer.

Craig, H., \& Perraton, H. (2003). Open and distance education for teachers' continuing professional development In B. Robinson \& C. Latchem (Eds.), Teacher education through open and distance learning: World review of distance education and open learning (Vol. 3, pp. 91-111). London, UK: Routledge/Falmer.

Deci, E. L., \& Ryan, R. M. (1985). Intrinsic motivation and self-determination in human behavior. New York, NY: Plenum.

Dörnyei, Z. (2003). Attitudes, orientations, and motivations in language learning: Advances in theory, research, and applications. Language Learning, 53(S1), 3-32. doi: 10.1111/1467-9922.53222

Dweck, C. S. (2008). Can personality be changed? The role of beliefs in personality and change. Current Directions in Psychological Science, 17(6), 391-394. doi: 10.1111/j.1467-8721.2008.00612.x

Dzakiria, H., Mustafa, C. S., \& Bakar, H. A. (2006). Moving forward with Blended Learning (BL) as a pedagogical alternative to traditional 
Aritonang, Motivation and Confidence of Indonesian Teachers 165

classroom learning. Malaysian Online Journal of Instructional Technology (MOJIT), 3(1), 11-18.

Gardner, R. C. (1985). Social psychology and second language learning: The role of attitudes and motivation. London, UK: Edward Arnold

Gardner, R. C., \& MacIntyre, P. D. (1991). An instrumental motivation in language study. Studies in Second Language Acquisition, 13(01), 57-72. doi: doi:10.1017/S0272263100009724

Lucas, R. I., Pulido, D., Miraflores, E., Ignacio, A., Tacay, M., \& Lao, J. (2010). A study on the intrinsic motivation factors in second language learning among selected freshman students. Philippines ESL Journal, 4, 3 $-23$.

MacIntyre, P. D., Dörnyei, Z., Clément, R., \& Noels, K. A. (1998). Conceptualizing willingness to communicate in an L2: A situational model of L2 confidence and affiliation. The Modern Language Journal, 82(4), 545-562. doi: 10.1111/j.1540-4781.1998.tb05543.x

MacIntyre, P. D., \& Gardner, R. C. (1991). Methods and results in the study of anxiety and language learning: A review of the literature. Language Learning, 41(1), 85-117. doi: 10.1111/j.1467-1770.1991.tb00677.x

Mahn, H., \& John-Steiner, V. (2002). The gift of confidence: A Vygotskian view of emotions.In G. Wells \& G. Claxton (Eds), Learning for life in the 21st century: socio-cultural perspectives of future education, (pp. 46-59). Oxford: Blackwell Publishing Ltd.

McClure, J. W. (2007). A blended approach in a graduate teaching assistants' pre-service course to promote self confidence. Paper presented at the ICT: Providing choices for learners and learning. Proceedings ascilite Singapore 2007.

McGroarty, M. (2001). Situating second language motivation. In Z. Dörnyei \& R. Schmidt (Eds.), Motivation and second language acquisition, (pp. 6990). Honolulu, HI: University of Hawai'i Press.

Motschnig-Pitrik, R., \& Mallich, K. (2004). Effects of person-centered attitudes on professional and social competence in a blended learning paradigm. Educational Technology \& Society, 7(4), 176-192. 
Paine, L. W., \& Fang, Y. (2006). Reform as hybrid model of teaching and teacher development in China. International Journal of Educational Research, 45(4-5), 279-289. doi: http://dx.doi.org/10.1016/j.ijer.2007.02.006

President of Republic of Indonesia. (2005). Undang-undang Republik Indonesia nomor 14 tahun 2005 tentang guru dan dosen (The Law of the Republic of Indonesia number 14 year 2005 about teachers and lecturers). Jakarta: Retrieved from http://search.4shared.com/postDownload/ oj4N0AbI/UU_No14_Tahun_2005.html.

Roth, W.-M. (2007). Emotion at work: A contribution to third-generation cultural-historical activity theory. Mind, Culture, and Activity, 14(1-2), 4063. doi: 10.1080/10749030701307705

Ryan, R. M., \& Deci, E. L. (2000). Self-determination theory and the facilitation of intrinsic motivation, social development, and well-being. American Psychologist, 55(1), 68-78. doi: 10.1037/0003-066X.55.1.68

Ushioda, E. (2001). Language learning at university: Exploring the role of motivational thinking. In Z. Dornyei \& R. Schmidt (Eds.), Motivation and second language acquisition, (pp. 93-125). Honolulu, HI: University of Hawai'i Press.

Ushioda, E. (2011). Language learning motivation, self and identity: Current theoretical perspectives. Computer Assisted Language Learning, 24(3), 199-210. doi: 10.1080/09588221.2010.538701

Vallerand, R. J. (1997). Toward a hierarchical model of intrinsic and extrinsic motivation. In M. P. Zanna (Ed.), Advances in experimental social psychology, (Vol. 29, pp. 271-360). San Diego, CA: Academic Press.

Vygotsky, L. S. (1978). Mind in society: The development of higher psychological processes. Cambridge, MA: Harvard University Press.

Ware, P. D. (2004). Confidence and competition online: ESL student perspectives on web-based discussions in the classroom. Computers and Composition, 21(4), 451-468. doi: http://dx.doi.org/10.1016/j.compcom. 2004.08.004 
Aritonang, Motivation and Confidence of Indonesian Teachers 167

Wertsch, J. V. (2008). From social interaction to higher psychological processes: A clarification and application of Vygotsky's theory. Human Development, 51(1), 66-79.

Woltering, V., Herrler, A., Spitzer, K., \& Spreckelsen, C. (2009). Blended learning positively affects students' satisfaction and the role of the tutor in the problem-based learning process: Results of a mixed-method evaluation. Advances in Health Sciences Education, 14(5), 725-738. doi: 10.1007/s10459-009-9154-6

Wu, W.-C. V., Yen, L. L., \& Marek, M. (2011). Using online EFL interaction to increase confidence, motivation, and ability. Journal of Educational Technology \& Society, 14(3), 118-129.

Yovetich, N. A., \& Rusbult, C. E. (1994). Accommodative behavior in close relationships: Exploring transformation of motivation. Journal of Experimental Social Psychology, 30(2), 138-164. doi: http://dx.doi.org/ 10.1006/jesp.1994.1007 